Proceedings

\title{
Towards Understanding the Health Aspects of the Processing of Lignocellulosic Fillers ${ }^{\dagger}$
}

\author{
Aleksander Hejna ${ }^{1, *}$ and Mariusz Marć ${ }^{2}$ \\ 1 Department of Polymer Technology, Gdańsk University of Technology, Narutowicza 11/12, \\ 80-233 Gdańsk, Poland \\ 2 Department of Analytical Chemistry, Gdańsk University of Technology, Narutowicza 11/12, \\ 80-233 Gdańsk, Poland; mariusz.marc@pg.edu.pl \\ * Correspondence: aleksander.hejna@pg.gda.pl; Tel.: +48-58-347-2234 \\ † Presented at the First International Conference on "Green" Polymer Materials 2020, 5-25 November 2020; \\ Available online: https://cgpm2020.sciforum.net/.
}

Citation: Hejna, A.; Marć, M. Towards Understanding the Health Aspects of the Processing of Lignocellulosic Fillers. Proceedings 2021, 69, 34. https://doi.org/10.3390/ CGPM2020-07218

Published: 5 November 2020

Publisher's Note: MDPI stays neutral with regard to jurisdictional claims in published maps and institutional affiliations.

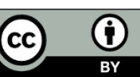

Copyright: (c) 2020 by the authors. Licensee MDPI, Basel, Switzerland. This article is an open access article distributed under the terms and conditions of the Creative Commons Attribution (CC BY) license (http://creativecommons.org/licenses/by/4.0/).

\begin{abstract}
Health and safety issues should be addressed during the development and investigation of industrial processes. In order to develop a sustainable process and fully evaluate its benefits and drawbacks for its optimization, it is crucial to determine its impact on the surrounding environment. This study aimed to assess the emission of volatile organic compounds during the modification of lignocellulosic fillers with passive dosimetry. Two types of processes were investigated: diisocyanate treatment of commercial lignocellulosic fillers in a batch mixer and thermo-mechanical treatment of brewers' spent grain using a twinscrew extruder. The presence of multiple terpenes and terpenoids was detected during the processing of fillers. The main compounds detected during modification were camphene, 3-carene, limonene, $\alpha$-pinene, and cymenes. These compounds can cause irritation and allergic reactions, according to the Globally Harmonized System of Classification and Labelling of Chemicals, as well as NFPA 704: Standard System for the Identification of the Hazards of Materials for Emergency Response. Some of them are also characterized by relatively low values of flash points, even below $40{ }^{\circ} \mathrm{C}$. Therefore, their emissions during the modification of cellulose materials should be carefully monitored, and proper precautions need to be taken.
\end{abstract}

Keywords: lignocellulosic fillers; volatile organic compounds; emissions; brewers' spent grain; modification

\section{Introduction}

There are multiple systems, standards, and indicators which define the health and environmental threats posed by particular chemicals. Among the most popular, which are often included in safety datasheets, the Globally Harmonized System of Classification and Labelling of Chemicals (GHS) and NFPA 704: Standard System for the Identification of the Hazards of Materials for Emergency Response [1,2] should be mentioned.

The Globally Harmonized System of Classification and Labelling of Chemicals is an internationally agreed standard which specifies the criteria for the assessment and evaluation of hazards, as well as for the preparation of harmonized safety datasheets providing essential data about chemical compounds. It describes chemicals using hazard statements and pictograms indicating their physical, health, and environmental properties and the threats they may pose to their surroundings.

The NFPA 704 system is commonly known as the "safety square" or "fire diamond" and enables quick and efficient identification of the risks related to the use of a particular compound and the selection of the proper handling procedure. This system was developed by the National Fire Protection Association from the United States to assess chemicals' flammability, health, and instability on a scale from 0 (minimal hazard) to 4 (severe hazard). Moreover, in exceptional cases, it also provides information about special hazards related to the material. 
As mentioned above, information related to the threats posed by particular chemicals is often included in datasheets. Nevertheless, except for their intentional use in well-defined and designed chemical reactions, different chemical compounds may also be generated in various more complex (in terms of chemistry) processes, e.g., related to the processing of waste or biobased materials, which could be applied as fillers for wood polymer composites [3]. Therefore, the impact on the environment should be taken into account during the development of sustainable processes to fully evaluate their benefits and drawbacks during optimization [4]. One of the possibilities is the emission of volatile organic compounds (VOCs), which is a crucial aspect of occupational safety and health [5]. In the presented work, we introduced passive dosimetry to aimed to assess the emission of VOCs during the modification of lignocellulosic fillers. Two types of processes were investigated: diisocyanate treatment of commercial lignocellulosic fillers in a batch mixer and thermo-mechanical treatment of brewers' spent grain (BSG) using a twin-screw extruder.

\section{Experimental}

\subsection{Materials}

In the presented study, we examined the three types of commercially available Arbocel $^{\circledR}$ fillers acquired from JRS J. Rettenmaier \& Söhne GmbH (Germany): B400, CW630PU, and UFC100. They were characterized by an average particle length of 900,40 , and $8 \mu \mathrm{m}$, respectively. Fillers B400 and UFC100 contained over $99.5 \%$ of cellulose, while the CW630PU filler was wood flour.

Their modifications were performed with four different isocyanates: hexamethylene (HDI), isophorone (IPDI), methylene diphenyl (MDI), and toluene (TDI), which were acquired from Sigma Aldrich (Poland). The purity of HDI, IPDI, and MDI was $98 \%, 99 \%$, and $98 \%$, respectively. For TDI, the mixture of 2,4-TDI and 2,6-TDI in the 80/20 ratio was used.

Brewers' spent grain used in the presented study was obtained from Energetyka Złoczew sp. z o.o. (Poland). It was already dried by the supplier. Brewers' spent grain was applied as a representative for waste lignocellulosic material, which after proper treatment, could be introduced into wood polymer composites. It is composed of cellulose, hemicellulose, and lignin, with moderate amounts of proteins and lipids, which may provide additional features to resulting composites [6].

\subsection{Modification of Lignocellulosic Fillers with Diisocyanates}

The investigated materials were modified in GMF 106/2 Brabender batch mixer at room temperature $\left(21.1-23.1^{\circ} \mathrm{C}\right)$ and rotor speed of $100 \mathrm{rpm}$. The fillers were mixed with a calculated amount of diisocyanate, 1.0, 2.5, 5.0, 10.0, or $15.0 \mathrm{wt} \%$, respectively, to the mass of filler. Mixing lasted for $5 \mathrm{~min}$, and then samples were stored in zipper bags.

Room temperature was applied to reduce the possible emissions of diisocyanates, which at $20-25^{\circ} \mathrm{C}$ show low vapor pressure $(7.0,0.04,0.0007$, and $4.0 \mathrm{~Pa}$, respectively for $\mathrm{HDI}$, IPDI, MDI, and TDI). At higher temperatures, their volatility is significantly increased. At $50^{\circ} \mathrm{C}$, the vapor pressure of TDI, IPDI, and MDI is increased 11.9, 22.5, and 33.5 times.

\subsection{Extrusion grinding of $B S G$}

BSG was thermo-mechanically treated using EHP $2 \times 20$ Sline co-rotating twin-screw extruder from Zamak Mercator (Poland), according to our patent application [7]. The used extruder has an L/d ratio of 40 . Parameters of the process were: throughput $-3 \mathrm{~kg} / \mathrm{h}$; screw speed $-225 \mathrm{rpm}$; barrel temperature $-60,120$, or $180{ }^{\circ} \mathrm{C}$. Then, BSG was left in order to cool down at room temperature.

\subsection{Assessment of VOCs Emissions}

Assessment of volatile organic compounds emissions during the processing of lignocellulosic fillers was carried out employing the Radiello ${ }^{\circledR}$ diffusive passive samplers (Fondazione Salvatore Maugeri, Padova, Italy) at the stage of analyte sampling from the gaseous 
phase. The mentioned passive sampler was equipped with a yellow diffusive membrane and the cylindrical container filled with sorption medium Carbograph 4 dedicated for VOCs sampling. Detailed characteristics of the Radiello ${ }^{\circledR}$ passive sampler were listed in detail elsewhere $[8,9]$. In brief, the analytical procedure aimed at the qualitative determination of VOCs present in the gaseous phase on the studied workplace included the following steps: (i) each time two independent Radiello ${ }^{\circledast}$ passive samplers were placed in the studied workplace, at a distance of more than $1 \mathrm{~m}$; (ii) the exposure time in the studied indoor environment was set up for $4 \mathrm{~h}$; (iii) sampling devices were placed close to the studied workplace and in the close neighborhood of the materials' preparation area; (iv) the temperature was monitored during whole working period and was $21.1-23.1^{\circ} \mathrm{C}$; (v) after the analytes sampling period, the containers with a sorption medium were removed from the diffusive membrane and placed inside glass tubes closed with polyethylene nut; (vi) containers with sorption medium were stored at $4{ }^{\circ} \mathrm{C}$ no longer than $12 \mathrm{~h}$ after sampling.

The identification of the main VOCs that occurs in the gaseous phase of the studied indoor environment was performed with the use of thermal desorption technique (Unity v.2, Markes International Ltd., Pontyclun, UK), connected with gas chromatography (Agilent Technologies 6890) combined with a mass spectrometer (5873 Network Mass Selective Detector, Agilent Technologies). The cylindrical containers filled with sorption medium were liberated at the temperature of $290^{\circ} \mathrm{C}$ by $15 \mathrm{~min}$. During this process, the analytes were transported to the microtrap. Then, the analytes were liberated from the microtrap heating up to $300^{\circ} \mathrm{C}$ and maintained by $5 \mathrm{~min}$ and transported by the helium flow rate $(1.5 \mathrm{~mL} \cdot \mathrm{min}-$ 1) to the GC capillary column (Agilent 122-5563, J\&W DB-5MS, $60 \mathrm{~m} \times 0.25 \mathrm{~mm} \times 1 \mu \mathrm{m}$ ). The GC oven temperature program was as follows: $50{ }^{\circ} \mathrm{C}$ for $1 \mathrm{~min}$, then raised at a rate of 10 ${ }^{\circ} \mathrm{C} \cdot \mathrm{min}-1 \mathrm{up}$ to $280{ }^{\circ} \mathrm{C}$ and maintained for $10 \mathrm{~min}$. The temperature of the TD-GC transfer line was set to $150^{\circ} \mathrm{C}$, and the temperature of the GC-MS transfer line was $280^{\circ} \mathrm{C}$. The employed mass spectrometer was working in a SCAN mode. Detailed information about the principals and characteristics of the thermal desorption technique were presented elsewhere $[10,11]$. In order to eliminate signals associated with other processes occurring in the laboratory hall and select only signals related to the performed modification, as well as to ensure the reliability of obtained results, the "background" was also analyzed.

\section{Results}

As mentioned above, the assessment of VOCs emissions is very important for the development of a truly environmentally friendly industrial process. Nevertheless, this factor is hardly investigated and described in the literature regarding the processing of lignocellulosic fillers. In Table 1, the main compounds detected during diisocyanate modification of fillers and brewers' spent grain thermo-mechanical treatment are summarized together with the properties characterizing their possible health impacts. Moreover, for all detected compounds, codes and pictograms are presented according to NFPA 704 and GHS standards [1,2].

The majority of detected compounds can be classified as terpenes and terpenoids. They are hydrocarbons and their derivatives containing additional functional groups. Terpenes and terpenoids are components of rosins, present in different plants, mostly conifers. Therefore they are often present in the lignocellulosic materials, such as wood flour or BSG [12]. Terpenes and terpenoids should be considered as a potential health threat due to their irritating and possibly allergic impact on human skin and eyes. They are described, e.g., with the following health statements according to GHS standards: H304-May be fatal if swallowed and enters airways; H315-Causes skin irritation; H319-Causes serious eye irritation; H335-May cause respiratory irritation; H371 - May cause damage to organs; H372Causes damage to organs through prolonged or repeated exposure. 
Table 1. Volatile organic compounds detected during the processing of lignocellulosic materials.

\begin{tabular}{|c|c|c|c|c|c|c|c|c|c|c|c|}
\hline Compound & Formula & Chemical Structure & $\begin{array}{c}\text { Boiling } \\
\text { Point, } \\
{ }^{\circ} \mathrm{C}\end{array}$ & $\begin{array}{c}\text { Vapor } \\
\text { Pres- } \\
\text { sure, } \\
\mathrm{Pa}\end{array}$ & $\begin{array}{l}\text { Flash } \\
\text { Point, } \\
{ }^{\circ} \mathrm{C}\end{array}$ & \multicolumn{3}{|c|}{$\begin{array}{c}\text { NFPA } \\
704 \\
\text { Codes }\end{array}$} & GHS Pictograms & $\begin{array}{l}\text { Lignocel- } \\
\text { Lulosic } \\
\text { Filler } \\
\text { Modifica- } \\
\text { tion } \\
\end{array}$ & $\begin{array}{c}\text { Extrusion } \\
\text { Grinding } \\
\text { of BSG }\end{array}$ \\
\hline Octanal & $\mathrm{C}_{8} \mathrm{H}_{16} \mathrm{O}$ & & 171 & 266 & 51 & 2 & 0 & 0 & & Yes & No \\
\hline$o$-Cymene & $\mathrm{C}_{10} \mathrm{H}_{14}$ & & 178 & 200 & 50 & 2 & 1 & 0 & & Yes & Yes \\
\hline m-Cymene & $\mathrm{C}_{10} \mathrm{H}_{14}$ & & 175 & 200 & 47 & 2 & 1 & 0 & & Yes & Yes \\
\hline$p$-Cymene & $\mathrm{C}_{10} \mathrm{H}_{14}$ & & 177 & 200 & 47 & 2 & 1 & 0 & & Yes & Yes \\
\hline Myrtenal & $\mathrm{C}_{10} \mathrm{H}_{14} \mathrm{O}$ & & 220 & 19 & 78 & 2 & 1 & 0 & & Yes & No \\
\hline Verbenone & $\mathrm{C}_{10} \mathrm{H}_{14} \mathrm{O}$ & & 227 & 10 & 85 & 2 & 2 & 0 & & Yes & No \\
\hline
\end{tabular}




\begin{tabular}{|c|c|c|c|c|c|c|c|c|c|c|c|}
\hline Compound & Formula & Chemical Structure & $\begin{array}{c}\text { Boiling } \\
\text { Point, } \\
{ }^{\circ} \mathrm{C}\end{array}$ & $\begin{array}{c}\text { Vapor } \\
\text { Pres- } \\
\text { sure, } \\
\mathrm{Pa}\end{array}$ & $\begin{array}{l}\text { Flash } \\
\text { Point, } \\
{ }^{\circ} \mathrm{C}\end{array}$ & \multicolumn{3}{|c|}{$\begin{array}{c}\text { NFPA } \\
704 \\
\text { Codes }\end{array}$} & GHS Pictograms & $\begin{array}{c}\text { Lignocel- } \\
\text { Lulosic } \\
\text { Filler } \\
\text { Modifica- } \\
\text { tion }\end{array}$ & $\begin{array}{c}\text { Extrusion } \\
\text { Grinding } \\
\text { of BSG }\end{array}$ \\
\hline$\alpha$-Pinene & $\mathrm{C}_{10} \mathrm{H}_{16}$ & & 156 & 633 & 33 & & 1 & 0 & & Yes & Yes \\
\hline$\beta$-pinene & $\mathrm{C}_{10} \mathrm{H}_{16}$ & & 166 & 391 & 36 & 3 & 1 & 0 & & Yes & No \\
\hline$\beta$-fenchene & $\mathrm{C}_{10} \mathrm{H}_{16}$ & & 157 & 526 & 25 & 2 & 3 & 1 & & Yes & No \\
\hline Camphene & $\mathrm{C}_{10} \mathrm{H}_{16}$ & & 160 & 333 & 34 & 3 & 2 & 1 & & Yes & Yes \\
\hline 2-Carene & $\mathrm{C}_{10} \mathrm{H}_{16}$ & & 168 & 496 & 38 & 2 & 2 & 0 & & Yes & No \\
\hline 3-Carene & $\mathrm{C}_{10} \mathrm{H}_{16}$ & & 170 & 496 & 46 & 2 & 2 & 0 & & Yes & Yes \\
\hline 4-Carene & $\mathrm{C}_{10} \mathrm{H}_{16}$ & & 168 & 555 & 38 & 2 & 2 & 0 & & Yes & No \\
\hline
\end{tabular}




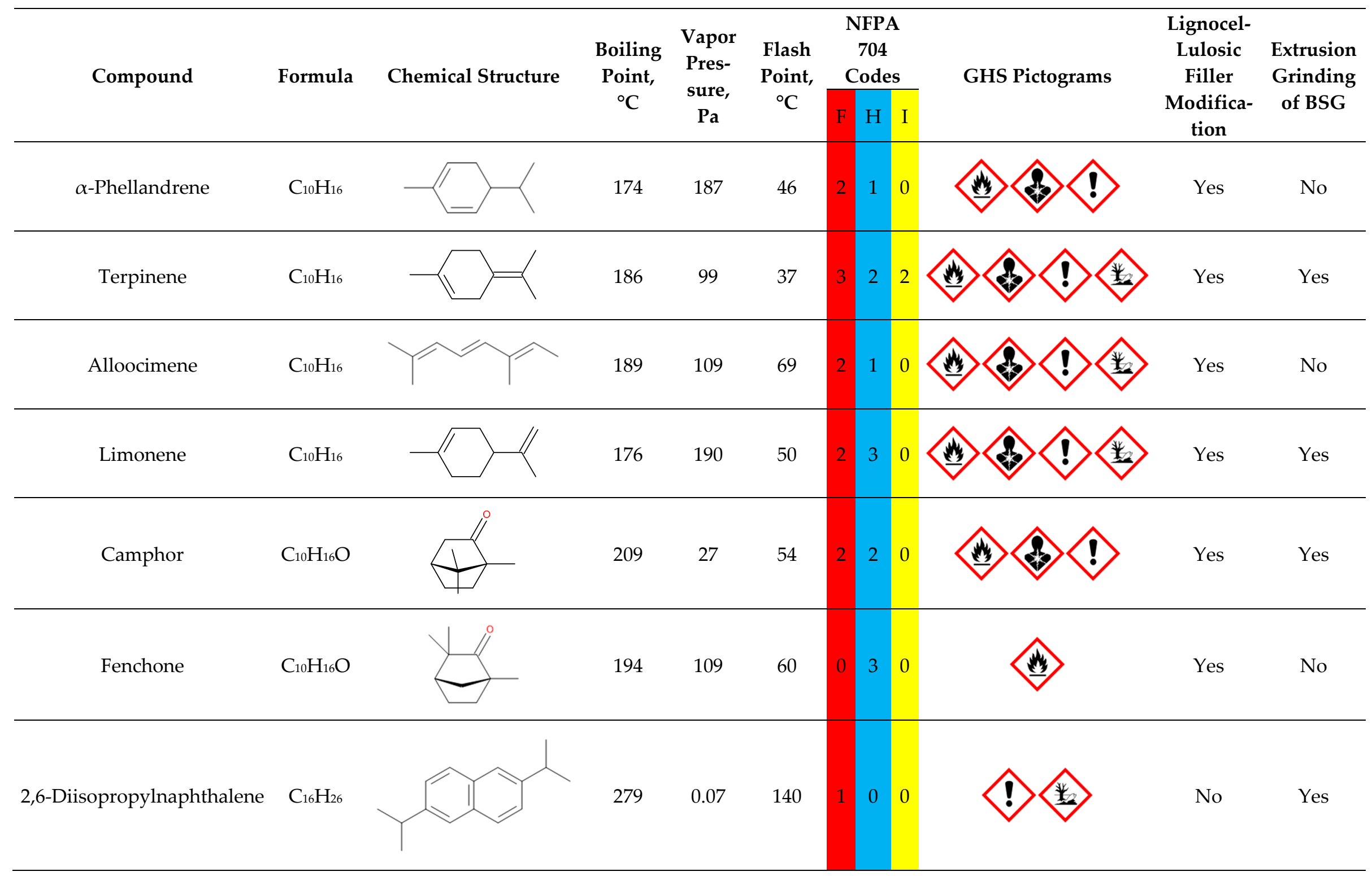


Moreover, except for health issues, terpenes and terpenoids may pose an environmental threat. Therefore they are categorized, e.g., according to the following statements: H400 - Very toxic to aquatic life; H410 - Very toxic to aquatic life with long-lasting effects; H411-Toxic to aquatic life with long-lasting effects; H412-Harmful to aquatic life with long-lasting effects.

Statements $\mathrm{H} 400$ and $\mathrm{H} 410$ are related to the high toxicity towards aquatic life, expressed by the lethal concentration $\mathrm{LC}_{50}$ lower than $1 \mathrm{mg} / \mathrm{L}$. For H411 and H412, its values are lower than 10 and $100 \mathrm{mg} / \mathrm{L}$, respectively. Moreover, statements pointing to the longlasting effect indicate the bioconcentration factor higher than 500 [13].

The majority of terpenes and terpenoids are characterized by significant flammability [14]. They are rated as 2 or 3 by the NFPA, indicating a flash point in the range of 37.893.3 and $22.8-37.8^{\circ} \mathrm{C}$, respectively. Moreover, compounds with a flash point below $60^{\circ} \mathrm{C}$ are marked as flammable according to GHS. The flammability of terpenes and terpenoids is a commonly known issue because their high content in particular species of wood increases fire threat [15]. Therefore, serious precautions should be taken during the processing of lignocellulosic fillers since they can ignite at relatively low temperatures.

It is also very interesting and actually very beneficial, considering the environmental friendliness of the diisocyanate modification process, that no traces of applied diisocyanates were detected during modification. Such an effect was related to the application of the ambient temperature, together with their low values of vapor pressure. Therefore, despite the common understanding of diisocyanates as very toxic, which is backed up by GHS standards (diisocyanates are categorized as irritating, allergic, harmful, or even fatal), their proper application for modification of lignocellulosic materials should be considered as relatively safe.

Regarding thermo-mechanical processing of BSG, the only compound that was not detected during the treatment of cellulose and wood flour was 2,6-diisopropylnaphthalene (DIPN). Although it was detected in relatively small amounts, its presence among emitted VOCs is justified. This compound is often applied as a plant growth regulator by farmers [16]. Therefore, it was not detected during the modification of cellulose and wood flour originated mostly from conifer trees. Regarding the safety of DIPN, it is not particularly harmful to humans but may pose a threat to the environment, mainly when generated in significant amounts, which could lead to its accumulation.

\section{Conclusions}

The presented paper aimed to investigate the emissions of volatile organic compounds during the processing of lignocellulosic fillers, which could be potentially introduced into polymer matrices. Two types of the processes were analyzed: the chemical modification of commercially available cellulosic fillers and the thermo-mechanical modification of waste material-brewers' spent grain. The majority of detected compounds can be classified as terpenes and terpenoids, among which the main were camphene, 3carene, limonene, $\alpha$-pinene, and cymenes. Their presence was related to the chemical structure and origin of investigated materials. Moreover, information related to the health and environmental threats posed by detected chemicals was provided. Future works should aim to complement the presented research by the quantitative analysis of particular volatile organic compounds' emissions and comparing them with their thresholds.

Acknowledgments: This work was supported by the National Science Centre (NCN, Poland) in the frame of SONATINA 2 project 2018/28/C/ST8/00187-Structure and properties of lignocellulosic fillers modified in situ during reactive extrusion.

Author Contributions: A.H. and M.M. conceived and designed the experiments; A.H. and M.M. performed the experiments; A.H. and M.M. analyzed the data; A.H. and M.M. contributed reagents/materials/analysis tools; A.H. wrote the paper. All authors have read and agreed to the published version of the manuscript.

Conflicts of Interest: The authors declare no conflict of interest. 


\section{References}

1. Regulation (EC) No 1272/2008 of the European Parliament and of the Council of 16 December 2008 on Classification, Labelling and Packaging of Substances and Mixtures, Amending and Repealing Directives 67/548/EEC and 1999/45/EC, and Amending Regulation (EC) No 1907/2006. Available online: https://eur-lex.europa.eu/LexUriServ/LexUriServ.do?uri=OJ:L:2008:353:0001:1355:EN:PDF (accessed on 10 September 2019)

2. NFPA 704: Standard System for the Identification of the Hazards of Materials for Emergency Response. Available online: https://www.nfpa.org/codes-and-standards/all-codes-and-standards/list-of-codes-and-standards/detail?code=704 (accessed on 10 September 2019)

3. Jorge, F.C. Reducing Negative Environmental Impacts from the Manufacturing and Utilization of Lignocellulosics-Derived Materials: An Overview on Research in 2007-2009. Mol. Cryst. Liq. Cryst. 2010, 522, 328-335. doi:10.1080/15421401003724118

4. Kalakul, S.; Malakul, P.; Siemanond, K.; Gani, R. Integration of life cycle assessment software with tools for economic and sustainability analyses and process simulation for sustainable process design. J. Clean. Prod. 2014, 71, 98-109. doi:10.1016/j.jclepro.2014.01.022

5. Colman Lerner, J.E.; Sanchez, E.Y.; Sambeth, J.E.; Porta, A.A. Characterization and health risk assessment of VOCs in occupational environments in Buenos Aires, Argentina. Atmos. Environ. 2012, 55, 440-447. doi:1016/j.atmosenv.2012.03.041

6. Mussatto, S.I.; Dragone, G.; Roberto, I.C. Brewers' spent grain: generation, characteristics and potential applications. J. Cereal Sci. 2006, 43, 1-14. doi:10.1016/j.jcs.2005.06.001

7. Hejna, A.; Formela, K. Sposób Suszenia i Rozdrabniania Młóta Browarnianego. Polish Patent Application P.430449, 2019.

8. Marć, M.; Namieśnik, J.; Zabiegała, B. Small-scale passive emission chamber for screening studies on monoterpene emission flux from the surface of wood-based indoor elements. Sci. Total Environ. 2014, 481, 35-46. doi:10.1016/j.scitotenv.2014.02.021

9. Marć, M.; Zabiegała, B.; Namieśnik, J. Application of passive sampling technique in monitoring research on quality of atmospheric air in the area of Tczew, Poland. Int. J. Environ. Anal. Chem. 2014, 94, 151-167. doi:10.1080/03067319.2013.791979

10. Król, S.; Zabiegała, B.; Namieśnik, J. Measurement of benzene concentration in urban air using passive sampling. Anal. Bioanal. Chem. 2012, 403, 1067-1082. doi:10.1007/s00216-011-5578-y

11. Zabiegała, B.; Partyka, M.; Gawrońska, A.; Wasilewska, A.; Namiesnik, J. Screening of volatile organic compounds as a source for indoor pollution. Int. J. Environ. Health 2007, 1, 13-28. doi:10.1504/IJENVH.2007.012222

12. Gaiolas, C.; Belgacem, M.N.; Silva, L.; Thielemans, W.; Costa, A.P.; Nunes, M.; Santos Silva, M.J. Green chemicals and process to graft cellulose fibers. J. Colloid Interf. Sci. 2009, 330, 298-302. doi:10.1016/j.jcis.2008.10.059

13. Globally Harmonized System of Classification and Labelling of Chemicals (GHS). Fourth revised edition. Available online: http://www.unece.org/trans/danger/publi/ghs/ghs_rev04/04files_e.html (accessed on 10 September 2019)

14. Dev, S. Terpenoids. In Springer Series in Wood Science; Wimmer, R., Ed.; Springer: New York, USA, $1989 ;$ pp. 691-807. https://doi.org/10.1007/978-3-642-74075-6_19

15. Ormeño, E.; Céspedes, B.; Sánchez, I.A.; Velasco-García, A.; Moreno, J.M.; Fernandez, C.; Baldy, V. The relationship between terpenes and flammability of leaf litter. Forest Ecol. Manag. 2009, 257, 471-482. doi:10.1016/j.foreco.2008.09.019

16. Brzozowski, R.; Skupiński, W.; Jamróz, M.H.; Skarżyński, M.; Otwinowska, H. Isolation and identification of diisopropylnaphthalene isomers in the alkylation products of naphthalene. J. Chromatogr. A 2002, 946, 221-227. doi:10.1016/s0021-9673(01)015710 . 